\title{
TRANSFORMACIÓN EN LA GESTIÓN DE PERSONAS EN EL CONTEXTO DE NUEVOS DESAFÍOS INSTITUCIONALES EN SERVICIO DE IMPUESTOS INTERNOS
}

\section{TRANSFORMATION IN PEOPLE MANAGEMENT IN THE CONTEXT OF NEW INSTITUTIONAL CHALLENGES ON INTERNAL REVENUE SERVICE}

\author{
Christian Hansen *
}

\section{Resumen}

Los distintos desafíos del servicio han generado la necesidad de hacer transformaciones para cumplir su misión institucional de aumentar la recaudación. Esto hizo necesario una nueva forma de gestionar el empleo y el desarrollo de las personas en el SII. Con esto, se generó un nuevo contexto, que es complementado con la Ley de Fortalecimiento del SII, el Instructivo Presidencial sobre Buenas Prácticas Laborales y los lineamientos de la Dirección Nacional del Servicio Civil en el marco de la modernización del Estado.

Este nuevo contexto es considerado en el Plan Estratégico del SII del año 2016, en cuya hoja de ruta para su implementación, se consideró el Desarrollo de las Personas como uno de sus cuatro ejes prioritarios. Ámbitos como formación, carrera, liderazgo, equipos, ambiente laboral, forman parte de él. El año 2017 en el marco de las nuevas definiciones estratégicas del SII, se establecen ejes que se incorporan a los anteriores.

Este documento es desarrollado como un relato de la experiencia de la Subdirección de Desarrollo de Personas del SII durante su proceso de modernización, que consistió principalmente en la implementación de un nuevo Modelo de Desarrollo de Personas que se traduce en diversos proyectos, y sus respectivos productos, vinculados en primera instancia al Eje Estratégico de Desarrollo de Personas y luego a su incorporación como elemento permanente en la gestión estratégica del Servicio.

Sus contenidos se exponen de modo que sean una herramienta que facilite la difusión de un modelo de gestión de personas replicable y escalable en instituciones similares, tanto a nivel nacional como internacional, constituyéndose al mismo tiempo en cimiento de la gestión del conocimiento al interior del SII. Por eso, está dirigido a diversos públicos, como especialistas en áreas de gestión de personas o recursos humanos, directivos de instituciones públicas, profesionales, entre otros.

Palabras clave: Desarrollo de las Personas, Modelo de Gestión de Personas, Modernización.

\footnotetext{
* Administrador Público, Magíster en Dirección de Organizaciones y Personas y docente de Magíster, Diplomados y Pregrado en la Universidad de Chile, Universidad de Santiago, Universidad de Concepción, Universidad Central, y Flacso Chile. Correo: ch.hansenc@gmail.com. ORCID https://orcid.org/0000-0001-7874-4550
} 


\begin{abstract}
The different challenges of the service have generated the need to make transformations in order to fulfill its institutional mission of increasing revenue collection. This made necessary a new way of managing the employment and development of people in the SII. With this, a new context was generated, which is complemented with the Law for Strengthening the SII, the Presidential Instruction on Good Labor Practices and the guidelines of the National Directorate of the Civil Service within the framework of the modernization of the State.

This new context is considered in the SII Strategic Plan of 2016, in whose roadmap for its implementation, People Development was considered as one of its four priority axes. Areas such as training, career, leadership, teams, work environment, are part of it. In 2017, within the framework of the new strategic definitions of the SII, axes are established that are incorporated to the previous ones.

This document is developed as an account of the experience of the People Development Subdirectorate of the SII during its modernization process, which consisted mainly in the implementation of a new People Development Model that translates into various projects, and their respective products, linked in the first instance to the Strategic Axis of People Development and then to its incorporation as a permanent element in the strategic management of the Service.

Its contents are presented as a tool to facilitate the dissemination of a people management model replicable and scalable in similar institutions, both at national and international level, becoming at the same time the foundation of knowledge management within the SII. Therefore, it is aimed at various audiences, such as specialists in the areas of people management or human resources, managers of public institutions, professionals, among others.
\end{abstract}

Keywords: People Development, People Management Model, Modernization.

Recibido: 02 de enero de 2021 / Aceptado: 14 de abril de 2021 


\section{Introducción}

\subsection{Modernización en la Gestión de Personas}

Tras el retorno a la democracia, el Estado requería una serie de transformaciones para enfrentar el desafío de posicionar una nueva lógica de administración del país y responder adecuadamente a las necesidades sociales que demandaban mayor apertura hacia nuevos actores y participación de la ciudadanía. El proceso de Modernización del Estado, que se implementó entre 1994 y 1999, responde precisamente a esta búsqueda de una mayor eficiencia y eficacia social en la labor pública.

Es así, como el Servicio de Impuestos Internos (SII) se concentró en la profesionalización y especialización de su dotación, aumentando en un $76 \%$ el número de profesionales en el periodo 1990-2008, e implementando el portal web www.sii.cl y diversas aplicaciones tecnológicas para simplificar los procesos tributarios y mejorar la atención de los contribuyentes.

Este impulso modernizador se establece en paralelo a la promulgación de la Ley sobre Nuevo Trato Laboral en 2003, que instaura el Sistema de Alta Dirección Pública para la elección más tecnificada de los altos cargos directivos, la profesionalización de la carrera funcionaria y una nueva institucionalidad para la gestión de personas en la administración pública.

Lo anterior, se refleja en la creación de la Dirección Nacional del Servicio Civil (DNSC) en el año 2004, que define un modelo basado en la transparencia, el mérito, la idoneidad para el ingreso y desarrollo de los altos cargos, específicamente a través el Sistema de Alta Dirección Pública y el fortalecimiento de la carrera funcionaria de otros niveles jerárquicos, con la definición de políticas y prácticas específicas del ciclo de vida laboral de los funcionarios públicos.

En el ámbito interno del SII, los lineamientos de la DNSC, sistematizados en el Código de Buenas Prácticas Laborales de 2006, son plasmados en el Plan Estratégico 2006-2010 de la Subdirección de Recursos Humanos del SII, vinculándose a subsistemas tales como planificación, organización del trabajo, gestión del empleo, gestión del rendimiento, gestión del desarrollo y gestión del cambio, de los que nacen diversas políticas y planes de acción, reflejados en 14 proyectos y sus respectivos productos.

De esta forma, el SII hizo propia la transformación y modernización de la gestión de personas, sumando a los lineamientos del Servicio Civil, su capacidad institucional de identificar oportunidades, planificar y ejecutar modelos y mecanismos de gestión para hacer sustentables los cambios en el tiempo. Logró establecer políticas y prácticas claras, confiables y reconocidas para procesos de reclutamiento, selección, inducción, capacitación, gestión del desempeño y promoción, entre otras materias, orientadas hacia los objetivos estratégicos de la institución, en el marco de un clima de respeto y confianza que favoreció la colaboración, participación y desarrollo de las personas. 
Estas transformaciones del SII estuvieron refrendadas por la reestructuración de la Subdirección de Recursos Humanos durante el 2007 (su último cambio había sido en 1992), las que apuntaron a la optimización de los procesos vinculados a los servicios del cliente interno, como formación, desarrollo y gestión de personas. Consecuentemente, también cambiaron los estilos de trabajo.

\subsection{Nuevas exigencias y desafíos}

Con una nueva década, vinieron nuevos desafíos para el Servicio de Impuestos Internos y sus personas.

En 2014, el programa de gobierno da un énfasis en el aumento del gasto público para inversiones sociales, como un impulso para disminuir la desigualdad, introducir más justicia social y otorgar mayores oportunidades y derechos.

Contar con mayores recursos para transformar el país se convirtió en un desafío, por lo que se levantó como la Ley de Reforma Tributaria (Ley 20.780 promulgada en septiembre de 2014), con el objetivo de aumentar la recaudación y equidad tributaria, incentivar el ahorro e inversión y disminuir la evasión y elusión.

Con lo anterior, la labor del SII debió hacer frente a desafíos como una mayor efectividad de la fiscalización, proveer más recursos y fortalecer la administración tributaria, además de mejorar los servicios y la atención a los contribuyentes, facilitando así el cumplimiento tributario.

Es en este contexto que las autoridades del Servicio impulsaron la promulgación de la Ley de Fortalecimiento Institucional, que estableció una serie de disposiciones vinculadas a la gestión y desarrollo integral de las personas, tales como: el aumento gradual de su planta, el ingreso entre 2014 y 2016 de 740 funcionarios mediante concursos que tuvieron en cuenta perfiles de desempeño y formación congruente con los objetivos de modernización con estándares de eficacia, eficiencia y probidad; y el desarrollo de carrera, que reconoce y potencia las capacidades y competencias, creando niveles de trabajos más especializados para el cumplimiento de las metas institucionales.

En esta perspectiva, el Instructivo Presidencial sobre Buenas Prácticas Laborales en Desarrollo de Personas en el Estado de 2016, vino a complementar la preocupación por un desarrollo integral de quienes laboran en las distintas reparticiones del Estado, abordando ejes como derechos, ambientes y condiciones laborales, entre otros. Concretamente, el Instructivo vincula al SII y a todas las instituciones del Estado con la gestión de personas, a través de la creación e implementación de políticas y prácticas que propendan a mejores empleos públicos y, de esta forma, fortalecer el aporte de quienes laboran en las distintas reparticiones.

Este nuevo escenario normativo, constituido por la Reforma Tributaria, la Ley de Fortalecimiento del SII, las orientaciones de la Dirección Nacional del Servicio Civil en el ámbito de gestión de recursos humanos y el Instructivo Presidencial sobre Buenas Prácticas 
Laborales en Desarrollo de Personas en el Estado, conforman el contexto del nuevo Plan Estratégico Institucional del SII 2015-2020.

\subsection{Hacia una nueva gestión de desarrollo de personas en el SII}

El Plan Estratégico 2015-2020 se construyó a través de un proceso participativo con todos los funcionarios, estamentos y asociaciones gremiales del SII que, a través de un diagnóstico compartido, formuló como punto de partida una misión y visión institucional consensuadas en las que se destaca el desarrollo de las personas como eje y condición ineludible para el éxito de la organización.

Por un lado, la misión, fundamento principal del quehacer institucional, quedó definida como:

"Procurar que cada contribuyente cumpla cabalmente sus obligaciones tributarias, aplicando y fiscalizando los impuestos internos de manera efectiva y eficiente, con estricto apego a la legalidad vigente y buscando la facilitación del cumplimiento, en el marco que establecen los principios de probidad, equidad y transparencia, en un ambiente de trabajo que propicie el desarrollo integral de los funcionarios, para lograr un desempeño de excelencia que aporte al progreso del país" (Servicio de Impuestos Internos, 2015).

Por otra parte, la visión, imagen que la institución desea comunicar, se acordó como:

"Seremos una institución pública reconocida, en el ámbito nacional e internacional, por la efectividad, eficiencia y autonomía en su gestión institucional; por incrementar y mejorar el control de la evasión y elusión, manteniéndolas en sus mínimos históricos, y potenciar el cumplimiento voluntario; por la equidad, probidad y transparencia en el ejercicio de su rol público; por disponer de soluciones tecnológicas innovadoras para el trabajo fiscalizador, la asistencia a los contribuyentes y el apoyo de otros organismos del Estado; y por contar con funcionarios altamente capacitados y comprometidos con el progreso del país" (Servicio de Impuestos Internos, 2015).

Cuando la nueva Dirección del SII asume en agosto del 2015, hace propia esta mirada común expresada en el Plan Estratégico y, a la luz del contexto político-normativo, elabora una Hoja de Ruta que define los énfasis de su gestión en concordancia con la implementación del Plan. A partir de esto, surgen cuatro Ejes Estratégicos: Modernización Institucional, Excelencia en la Gestión Interna, Desarrollo de las Personas y Fortalecimiento de las Comunicaciones.

Si bien todos estos ejes se vinculan al despliegue de la estrategia institucional del SII, es en el eje de Desarrollo de las Personas que, subyace la idea de reforzar la profesionalización de los recursos humanos, orientar las políticas de empleo del SII y el quehacer institucional a capacidades técnicas, cuyos criterios sean autónomos e independientes de las administraciones de Gobierno de turno, y que apunten a eficiencia, productividad y 
resultados. Este énfasis queda refrendado en el cambio de nombre de la Subdirección de Recursos Humanos, que en 2015 pasa a llamarse Subdirección de Desarrollo de Personas.

Para el año 2016, los cuatro ejes de la hoja de ruta comienzan su consolidación, definiéndose para el período 2017 cuatro nuevos ejes estratégicos, los cuales complementando los anteriores, se han definido como prioridades institucionales. Estos son: la Transversalización del Modelo de Gestión del Cumplimiento Tributario; la implementación del nuevo Modelo de Atención y Asistencia al Contribuyente; completar la implementación de la Reforma Tributaria; y la instalación del Modelo de Gestión por Procesos. La gestión de estas nuevas prioridades, derivó en planes que operacionalizarán lo señalado en los ejes. Estos planes operativos de aplicación transversal, fueron coordinados por las áreas responsables y monitoreados en su conjunto para asegurar que los cuatro nuevos ejes se instalaran en la gestión local de las Direcciones Regionales y en las Subdirecciones. En paralelo, la puesta en marcha de dichos planes fue acompañada por diversas estrategias y proyectos en desarrollo de personas (liderazgo, equipos y gestión de cambio) para asegurar la correcta instalación de las prácticas, procesos y procedimientos derivados de los ejes.

Por último, y en conformidad al Plan Estratégico móvil del Servicio (2015), para el 2018 se da continuidad a los ejes de Transversación del Modelo de Gestión de Cumplimiento Tributario; Implementación del Modelo de Atención y Asistencia al Contribuyente; Consolidación del Modelo de Gestión por Procesos y se incluye un cuatro Eje de Ética Institucional y Mejores Prácticas. Este último eje, busca declarar dentro de las prioridades estratégicas, aquellos aspectos de carácter adaptativos, que deben estar presentes de manera transversal en cada una de las acciones del SII, y visibilizar los desafíos y cambios a los cuales se enfrenta la organización en el ejercicio diario de su función.

Al igual que en los años anteriores, la Subdirección de Desarrollo de Personas mantiene su impulso generando proyectos y programas para acompañar el proceso de instalación de las nuevas directrices, tendientes a fortalecer y desarrollar las habilidades de liderazgo de los equipos directivos del Servicio, promover un mejor clima y espacios de trabajo colaborativos e integradores, fortaleciendo la gestión de personas como foco para la instalación de prácticas que favorezcan las transformaciones organizacionales derivadas de los objetivos estratégicos institucionales.

\section{Desarrollo}

Considerando los desafíos que el Plan Estratégico Institucional y su Hoja de Ruta imponen al Servicio, fue necesario modernizar el Modelo de Recursos Humanos del Servicio de Impuestos Internos, definido el año 2006, por un nuevo Modelo de Desarrollo de Personas, con el objeto de dar respuestas eficientes a estas demandas, concentrando sus esfuerzos en mejorar los procesos de gestión de personas y en la incorporación de mejores prácticas al interior del Servicio. 
El Modelo da respuesta al contexto particular en que se encuentra el Servicio, y busca a través de un enfoque sistémico, orientar los esfuerzos de la gestión de personas a la mejora continua de los desempeños individuales y grupales con el fin de propender al cumplimiento de los objetivos de la institución.

\section{Imagen $\mathrm{N}^{\circ}$ 1: Modelo de Desarrollo de Personas}

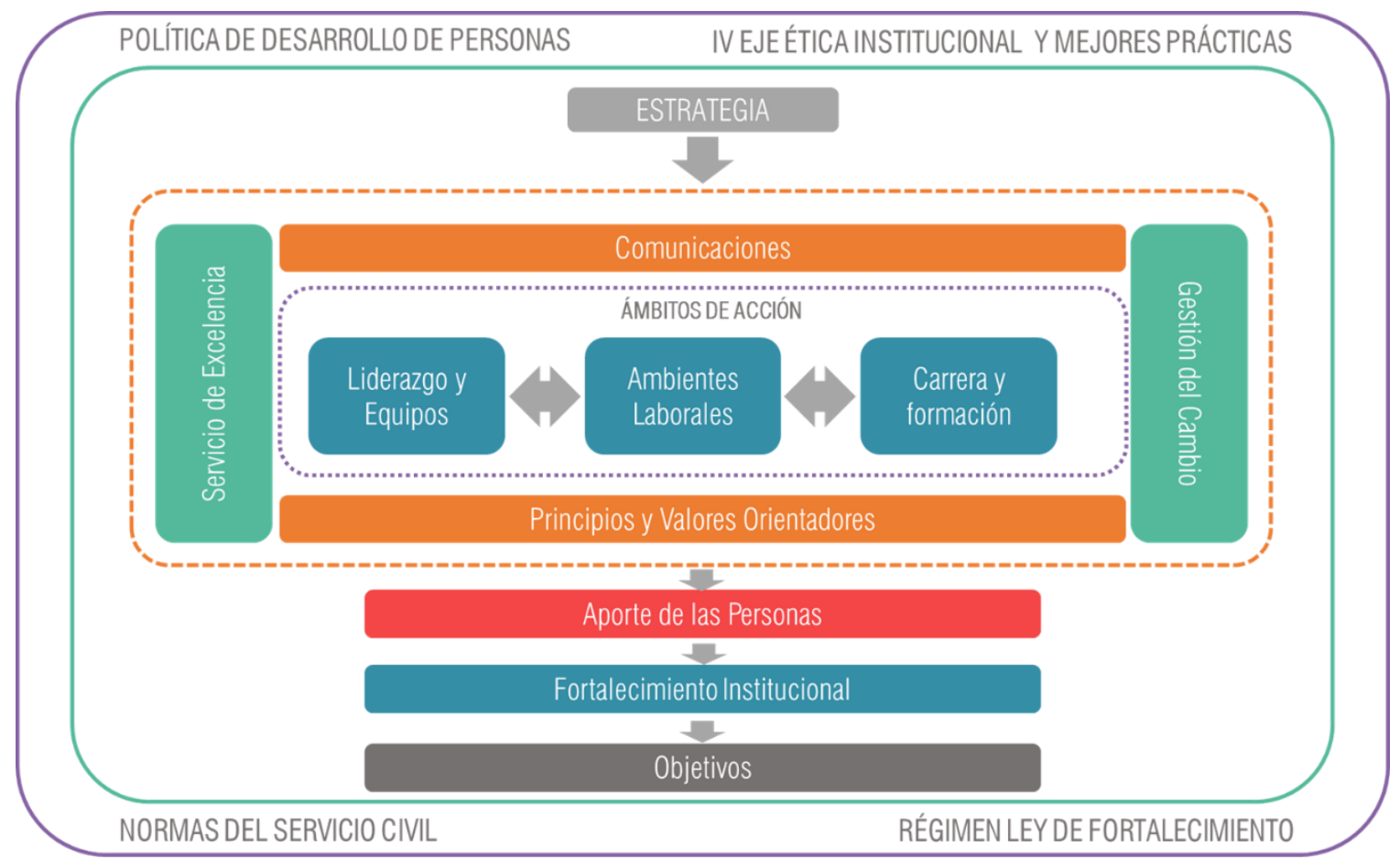

Fuente: Servicio de Impuestos Internos, 2016

Se identificaron tres ejes estratégicos, ámbitos que consolidan el quehacer de la Subdirección de Desarrollo de Personas:

El primero de ellos, Liderazgo y Equipos, tiene el propósito de dotar a la organización de equipos que den respuesta al cumplimiento de los objetivos y metas institucionales, logrando el equilibrio permanente entre productividad y efectividad con un adecuado ambiente laboral y excelencia. A través del ejercicio de un estilo de liderazgo institucional que propicie dichos propósitos, valorando la mirada común y la obtención de resultados colectivos por sobre los individuales.

El segundo eje estratégico, Ambientes Laborales, busca desarrollar un ambiente laboral basado en el respeto, confianza, reconocimiento y colaboración mutua, promoviendo la motivación y el compromiso de los funcionarios/as frente a los objetivos y metas organizacionales, a través del desarrollo de acciones vinculadas a Clima Laboral, Mesas de Trabajo e implementación del Instructivo Presidencial y la Gestión del Bienestar. 
El tercer eje Carrera y Formación se dedica a impulsar el desarrollo de los funcionarios del Servicio, realizando con eficiencia los procesos involucrados en todo el ciclo laboral de una persona. Con especial énfasis en su formación y desarrollo de carrera.

A su vez, existen para la implementación del modelo lineamientos transversales prioritarios y que se refieren a:

a) Servicio de Excelencia: Considera instalar una visión de Servicio de Excelencia, a través del mejoramiento continuo de las políticas, procedimientos y servicios, para cumplir con las expectativas y los requerimientos de los clientes internos, buscando con esto impactar positivamente en el logro de los objetivos organizacionales.

b) Gestión del Cambio: Se refiere a facilitar los procesos de cambio organizacional, su implementación, seguimiento y consolidación, instalando a la Subdirección como un socio estratégico dentro del Servicio.

c) Gestión de las Comunicaciones: Consiste en participar de las estrategias comunicacionales para impulsar y movilizar los distintos cambios y proyectos institucionales. Establece un modelo efectivo de comunicación dentro de la Subdirección y hacia el resto de la organización, con el propósito de generar mayor sinergia interna, así como también una promoción constante de los proyectos e iniciativas hacia el resto de la institución.

d) Principios y Valores orientadores: Además de la práctica de los valores institucionales, la Subdirección, adoptó como rasgos distintivos de su desempeño, los siguientes valores: Confianza, Colaboración, Innovación y Orientación a los Objetivos.

Este modelo ha logrado posicionar a la Subdirección de Desarrollo de Personas como un socio estratégico, preocupado del desarrollo permanente de las personas que se desempeñan en el SII. Ha permitido también, tener una mirada sistémica de los procesos internos apuntando a la mejora continua, innovación y excelencia del servicio. Contribuyendo con esto a facilitar los cambios organizacionales y el cumplimiento de los lineamientos Institucionales.

Junto con la implementación de este modelo, se fortaleció la estructura de la Subdirección de Desarrollo de Personas, considerando el valor que cada uno de los miembros aporta. Se realizaron diversas actividades de participación, diseño y difusión del modelo y se fortaleció la Consultoría de Desarrollo Organizacional a nivel nacional, contribuyendo con esto, a instalar la mirada de las personas en cada uno de los lugares de trabajo.

Diversas son las experiencias, proyectos y acciones que están surgiendo y surgirán en el despliegue de este modelo, cuyos cimientos, como se ha descrito, se fundan en nuevas exigencias institucionales y en una mirada que pone a las personas en el centro para la consecución de los objetivos. 


\subsection{Eje Liderazgo y Equipos}

\subsubsection{Aspectos generales}

Considerar el Desarrollo de Personas como un eje prioritario dentro del Plan Estratégico Institucional, expresa el compromiso y el reconocimiento de la importancia que tienen las personas que componen el SII para el cumplimiento de los nuevos desafíos y exigencias institucionales para mejorar la gestión interna y los resultados.

El rol que juegan las personas no se da en un contexto aislado de individualismos, en que cada una responde a un mundo propio, sino que se entiende como un universo compartido, en que éstas forman parte de un todo y, que como tal, son engranajes de un nuevo Modelo de Desarrollo de Personas, de una visión y misión institucional compartidas.

Uno de los ejes señalados en la descripción del Modelo de Desarrollo de Personas, es el de Liderazgo y Equipos. Como refleja su nombre, se compone de dos partes. La primera apunta a la necesidad de encabezar la gestión de personas, a través de "fortalecer y desarrollar un estilo de liderazgo que contribuya a la gestión del quehacer institucional y que permita potenciar los resultados e incrementar los niveles de satisfacción laboral"; en tanto la segunda se asocia a contar con una fuerza colectiva que de soporte a dicha gestión, en otras palabras "equipos que permitan dar respuesta a las demandas institucionales, logrando el equilibrio permanente entre productividad, cumplimiento de metas y efectividad con un adecuado ambiente laboral y excelencia institucional".

En el caso de Liderazgo y Equipos, resulta esencial la construcción de estilos de liderazgo y de equipos que sean congruentes con la definición del Desarrollo de Personas, con los ejes estratégicos y que apunte al proceso de modernización del SII para el cumplimiento de sus objetivos institucionales. En definitiva, se trata de incorporar nuevas prácticas de trabajo en las jefaturas y equipos para asumir nuevos desafíos y adecuarse a las exigencias de un contexto que ha llevado al SII a replantearse su misión y visión institucional a través de un Plan Estratégico de cara al futuro y que fija ejes prioritarios.

Los cambios que implica asumir una nueva carta de navegación, necesitan comprensión, compromiso e involucramiento. Crucial es entonces la conducción que se tenga y la disposición para llevar a cabo los procesos de cambio necesarios. A eso apunta el eje de Liderazgo y Equipos, que tienen a la base una lógica apalancadora de los cambios y transformaciones organizacionales.

Entendiendo que este compromiso e involucramiento debe ser permanente y sustentable, el SII lo formaliza mediante la emisión de una nueva Política Institucional para el Ejercicio del Liderazgo por parte de las Jefaturas, a través del Oficio Circular $\mathrm{N}^{\circ} 21$ del 10 de Agosto del 2018. Este documento establece un marco regulatorio que alinea el ejercicio del rol de las Jefaturas del Servicio, para asegurar la eficaz conducción de la organización para el cumplimiento de su misión. 
Este contexto institucional, proporciona el escenario adecuado para la generación de proyectos y programas para Fortalecer el Estilo de Liderazgo Institucional y las habilidades para conducir eficazmente las transformaciones organizacionales.

\subsubsection{Fortalecimiento de un Estilo de Liderazgo Institucional}

Antes de abordar los distintos alcances de este proyecto, en primer lugar, es necesario definir el concepto, qué se entiende por liderazgo al interior del SII.

El Liderazgo es la capacidad para conducir un equipo hacia el cumplimiento de su misión. Pero no de cualquier forma o por cualquier medio, sino que, motivando el compromiso de las personas con las metas establecidas, generando instancias que promuevan el desarrollo de los conocimientos y habilidades de ellas, a través del ejercicio de la retroalimentación y comunicación permanente.

El liderazgo, entendido así, implica en definitiva la habilidad del líder para establecer interacciones positivas que se adecúen al nivel de desarrollo de sus colaboradores y se vinculen a principios que faciliten la toma de decisiones oportunas, la responsabilidad en los resultados, la facilitación y movilización de los cambios organizacionales, el fomento de la excelencia, el cumplimiento de metas y objetivos institucionales, el reconocimiento de las personas, el conocimiento y expertise técnica, y el apego a las normas y al código de ética institucional.

Haciendo suya esta perspectiva, el Proyecto de Fortalecimiento de un Estilo de Liderazgo Institucional busca empoderar a las jefaturas del SII en su rol, generando habilidades para impulsar los cambios organizacionales, la gestión del desempeño y el desarrollo de sus equipos de trabajo, junto con consolidar sus habilidades de conducción para alcanzar resultados colectivos de excelencia para la institución.

En definitiva, se trata de fortalecer la manera en que los jefes ejercen sus funciones para conducir, motivar, valorar, relacionarse y dialogar con sus equipos.

El modelo de Liderazgo Institucional del SII identifica los ámbitos de acción por los cuales las jefaturas transitan para gestionar eficazmente el desempeño y desarrollo de su equipo, dichos ámbitos se operacionalizan en atributos los que deben ir potenciándose mediante la implementación de acciones concretas para ello. 


\section{Imagen $\mathbf{N}^{\circ}$ 2: Modelo de Liderazgo Institucional SII}

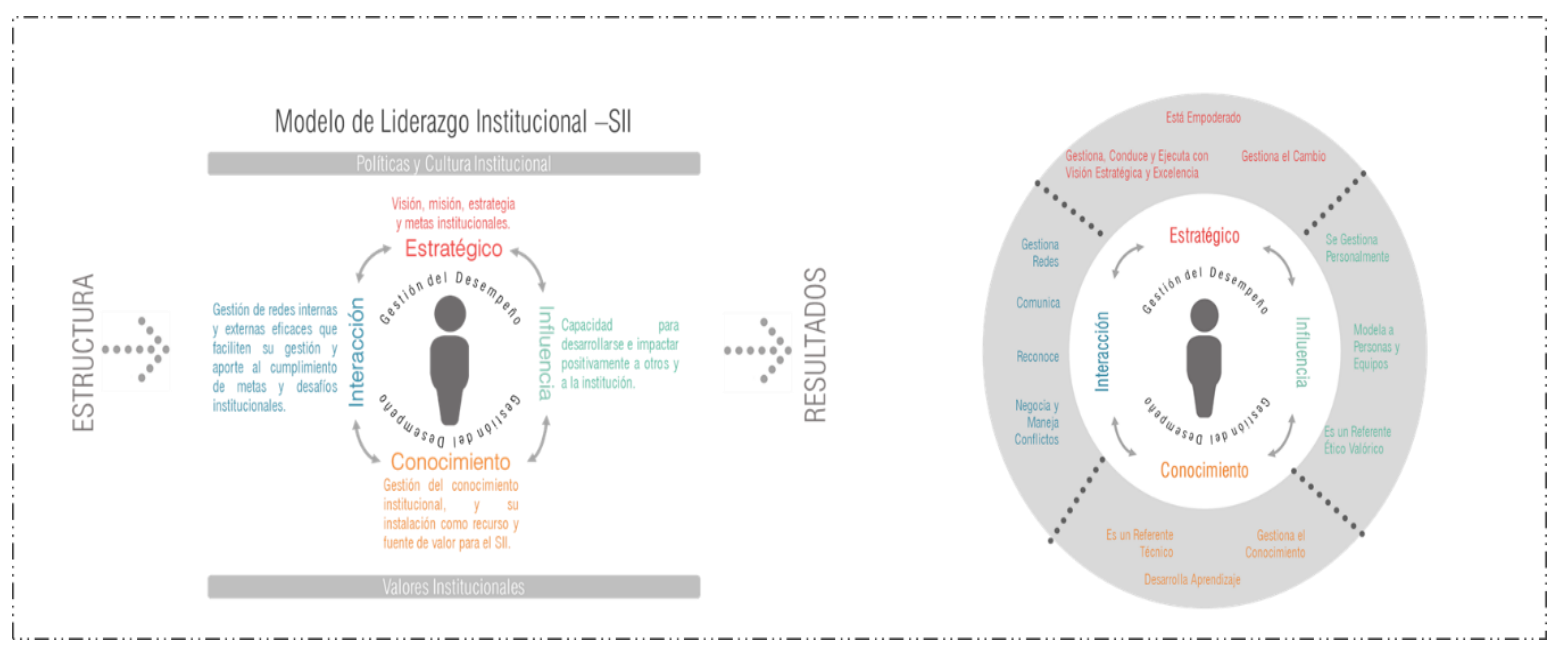

Fuente: Servicio de Impuestos Internos, 2016

Estos ámbitos son: el Estratégico, conformado por la visión, misión, estrategia y metas institucionales; el del Conocimiento, vinculado a la gestión del conocimiento institucional y su instalación como recurso y fuente de valor para la institución; el de la Influencia, asociado a la capacidad para desarrollarse e impactar positivamente a otros y a la institución; y el de la Interacción, relacionado a la gestión de redes internas y externas eficaces que faciliten su gestión y aporte al cumplimiento de metas y desafíos institucionales.

Dichos ámbitos y atributos configuran el camino del líder en su rol y se asocian, al mismo tiempo, con las políticas, cultura y valores institucionales definidos en el Plan Estratégico del SII, a partir de un contexto de nuevas necesidades del país, como se describió en capítulo anterior, conformando, todos estos elementos, el modelo de liderazgo del SII.

Para concretar el propósito del Proyecto de Fortalecimiento de un Estilo de Liderazgo Institucional, se desarrolló un plan de formación y entrenamiento para las jefaturas del SII, que permitiría empoderar a las jefaturas del SII en su rol, desarrollando habilidades para impulsar los cambios organizacionales, la gestión del desempeño y desarrollo de sus equipos de trabajo, y consolidar sus habilidades de conducción con el propósito de alcanzar resultados colectivos de excelencia para la institución.

Tras un diagnóstico inicial que estableció las fortalezas y ámbitos de mejoras para todas las jefaturas y Directivos del SII en relación al modelo de Liderazgo de la institución, se proyectó un trabajo a partir del año 2016 y que se mantiene al día de hoy. Este trabajo implicó inicialmente, el desarrollo de actividades de formación en las Direcciones Regionales y Dirección Nacional (talleres teórico-prácticos), coaching por parte del equipo 
de consultores Regionales y de la Dirección Nacional para el desarrollo e incorporación de nuevas prácticas de trabajos individuales y grupales en base al modelo. Actualmente, hemos incluido un proceso de evaluación de brechas, de forma que el proceso de acompañamiento permanente realizado por los Consultores focalice en las características individuales de cada jefe y/o Directivo, favoreciendo su aprendizaje individual de los atributos del modelo.

Este proceso ha permanecido activo en el tiempo, abarcando actividades de formación y acompañamiento directivo para los Subdirectores, Directores Regionales y Jefaturas de $3^{\circ}$ y $4^{\circ}$ nivel, focalizando distintos aspectos del modelo de liderazgo en consonancia con las necesidades estratégicas del Servicio y de lo que se espera del desempeño de sus Jefaturas.

\subsubsection{Desarrollo de equipos de Alto Desempeño}

De acuerdo a algunos referentes de la literatura existente en esta área, el concepto de equipo se utiliza sin tener necesariamente en cuenta su real significado. Por ello, algunos autores hacen la diferencia entre grupos y equipos de trabajo. La diferencia entre ambos radica en el propósito común, mientras en los grupos persisten las individualidades, en los equipos prima el resultado colectivo, el compromiso con una meta y el aporte de cada uno de los integrantes de dicho equipo en el resultado final.

Jon Katzenbach y Douglas Smith (1993) definen equipo como "un pequeño número de personas con habilidades complementarias, que están comprometidas con un propósito, un conjunto de metas de desempeño y un enfoque común, por los cuales se hacen mutuamente responsables".

El proyecto de Desarrollo de Equipos de Alto Desempeño del SII parte de esta premisa, que se conecta a su vez con los desafíos, estrategia y los valores institucionales. Existe aquí no sólo el compromiso y cohesión con un propósito, que sería la característica base de cualquier equipo, sino que también un sentido de responsabilidad individual y colectiva, en la que importa tanto el éxito de uno como del otro. Esta última premisa, marca la diferencia y hace que un equipo tenga una respuesta de alto desempeño.

La siguiente ilustración corresponde al modelo de Desarrollo de Equipos de Alto Desempeño del SII. 


\section{Imagen $N^{\circ}$ 3: Modelo de Desarrollo de Equipos de Alto Desempeño SII}

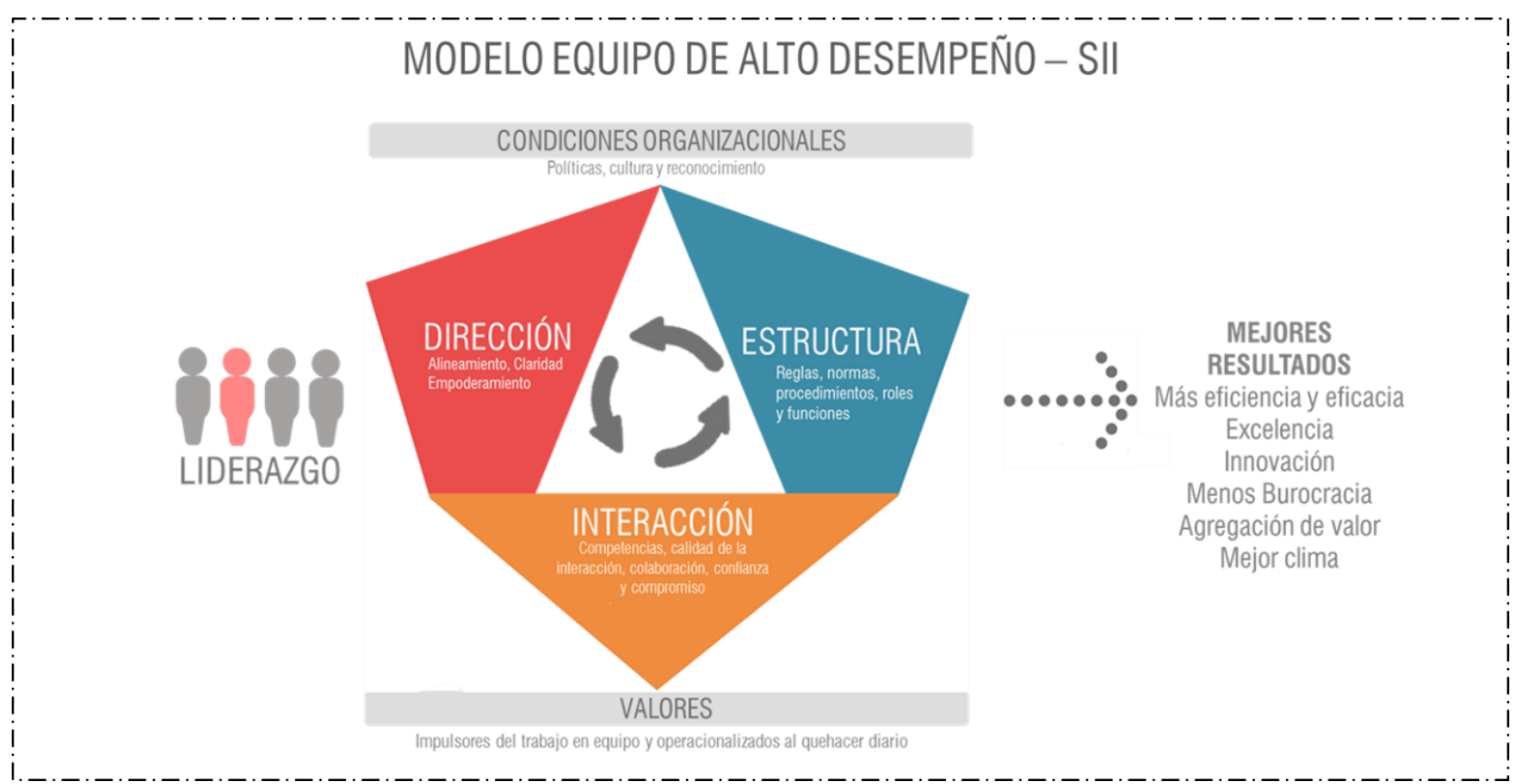

Fuente: Servicio de Impuestos Internos, 2016

En el modelo de Desarrollo de Equipos de Alto Desempeño del SII confluyen tres ámbitos: Dirección, Estructura e Interacción, cada uno de los cuales contempla distintos atributos que los equipos deben desarrollar para manifestar una respuesta de alto desempeño; todo en el marco de los valores institucionales, como impulsores del trabajo en equipo en el quehacer diario, y las condiciones organizacionales, referidas a las políticas, cultura y reconocimiento.

La Dirección, contempla el camino por el cual transita un equipo, otorgando sentido e identidad, desde su posición y la valoración del aporte del equipo en el cumplimiento de las metas y objetivos organizacionales. Dentro de los atributos que lo componen encontramos el alineamiento: que refleja que el equipo reconoce y valora el propósito de la organización, comprometiéndose con sus desafíos y agregando valor desde su quehacer cotidiano; y la claridad: que significa que el equipo conoce su propósito, objetivos y que las metas que persigue son alcanzables, desafiantes y responden a un plan de trabajo reconocido y validado por todos sus integrantes. El empoderamiento tiene que ver con que se reconoce al líder presente en el equipo y se valora su aporte, y que éste, por su parte, es capaz de delegar responsabilidades de acuerdo a lo que demandan las circunstancias o contexto, favoreciendo de esta forma la autonomía de los integrantes y haciéndolos responsables del desempeño y resultado del equipo.

La Estructura, tal como su nombre lo indica, este ámbito proporciona el contexto inmediato de acción del equipo. Dentro de sus atributos se incluyen las normas, reglas y procedimientos: que son establecidas de manera colectiva por parte del equipo para regular y facilitar su desempeño, la innovación a través del incentivo del aprendizaje continuo, y 
para contribuir a declarar las expectativas en cuanto a la calidad de los procesos y sus resultados. Los roles y funciones: de cada miembro son conocidos por el equipo, y si bien se reconoce la importancia del líder para el desempeño del equipo, existe flexibilidad para asumir nuevos roles $y$ funciones de acuerdo a las contingencias y exigencias organizacionales.

La Interacción, refiere al punto de equilibrio entre la Dirección y la Estructura, ya que estos ámbitos se desarrollan en menor o mayor medida siempre y cuando exista una interacción positiva entre los miembros del equipo. En este caso, el equipo promueve la interacción entre sus miembros sobre la base de la confianza, del saber escuchar, del respeto, del sentido de pertenencia y de la participación en la toma de decisiones, con una comunicación fluida y que facilita los procesos de trabajo, donde los conflictos y diferencias se enfrentan de manera constructiva, aportando a la generación de un ambiente positivo. Así mismo conocer las competencias del equipo refleja el conocimiento de las habilidades de cada uno de sus integrantes, estableciendo relaciones complementarias para mejorar los resultados, siendo flexibles ante situaciones de cambio y promoviendo la gestión de éste para alcanzar resultados de excelencia.

Se proyectó una intervención para el desarrollo de equipos de alto desempeño en todo el SII. Para ello se estructuró una intervención con distintas fases, cuya metodología fueron entrevistas, reuniones y talleres, sesiones de acompañamiento individual y grupal, involucrando a la totalidad de las Jefaturas y Directivos del Servicio.

En el diagnóstico, se hizo un análisis situacional, descubriendo las principales fortalezas y las oportunidades de mejora que surgen a partir de ellas. El acompañamiento a las jefaturas buscó potenciar la habilidad de desarrollar en sus equipos nuevas prácticas de trabajo para generar una respuesta de alto desempeño, a través de la gestión efectiva de personas y empoderamiento de su rol. Los talleres con equipos apuntaron a desarrollar el sentido de pertenencia, generando propósito compartido y visión de valor del trabajo colectivo por sobre el individual. La última fase de intervención, así como el acompañamiento de equipos, se centró en fortalecer aspectos trabajados en talleres y así colaborar en la instalación de nuevas prácticas de trabajo y aprendizajes que potenciarán la interacción de los integrantes del equipo. A partir de este trabajo con el director del SII, subdirectores y sus respectivos equipos, se logró concretar el Proyecto de Desarrollo de Equipos de Alto Desempeño.

\subsection{Eje Ambientes Laborales}

\subsubsection{Aspectos generales}

Como se señaló, el Desarrollo de Personas ha sido uno de los ejes prioritarios del Plan Estratégico del SII, respondiendo entre otros aspectos, al Instructivo Presidencial sobre Buenas Prácticas Laborales en Desarrollo de Personas en el Estado, desarrolladas desde el 
año 2015 y a las orientaciones de la Dirección Nacional del Servicio Civil (DNSC) en materia de normas de aplicación general en Gestión y Desarrollo de Personas.

Los principios orientadores del Instructivo Presidencial se basaron en entregar un mejor servicio a la ciudadanía por parte del Estado, a través respuestas de calidad, eficientes y eficaces para resolver las necesidades, y de manera oportuna. Para ello, surge la necesidad de contar a la vez con servidores públicos preparados para asumir las mayores complejidades de la gestión pública.

Lo anterior radica en un empleo público de calidad, coherente con estándares internacionales, con base en un Estado moderno, innovador y transparente, que promueva la igualdad de oportunidades, facilite el diálogo, la inclusión y la participación de las personas que laboran en la administración pública, y de la ciudanía en general. Un Estado que otorgue un servicio de calidad, al mismo tiempo que un buen trato y condiciones laborales dignas, para contar con funcionarios reconocidos y preparados, comprometidos y motivados en el ejercicio de sus funciones, de manera de garantizar mérito, un desempeño eficaz, responsabilidad, probidad, innovación y adhesión a los principios y valores del SII.

Asimismo, se entregan lineamientos relativos al cumplimiento de estándares en Ambientes Laborales y Calidad de Vida Laboral, para que los servicios públicos desarrollen acciones que promuevan ambientes laborales saludables, de mutuo respeto y no discriminación, propendiendo a mejorar los grados de satisfacción, la calidad de vida laboral y el bienestar físico, psicológico y social por parte de las personas en su labor y en su entorno de trabajo, con el fin de aumentar la productividad, cumplir con los objetivos institucionales y así entregar mejores servicios a la ciudadanía.

En el Plan Estratégico 2018-2022 del SII, al incorporar el eje Ética Institucional y Mejores Prácticas, se involucra el apego y respeto a las normas, la ética pública, los valores institucionales y el desarrollo de mejores prácticas laborales en diversos ámbitos.

A su vez, a partir del año 2018 la DNSC establece las Normas de Aplicación General en Gestión y Desarrollo de Personas, dando continuidad a lo desarrollado en el marco del Instructivo Presidencial sobre Buenas Prácticas Laborales en Desarrollo de Personas en el Estado.

En este contexto, Ambientes Laborales es uno de los ejes estratégicos del Modelo de Desarrollo de Personas del SII. Esto se ha traducido en el establecimiento de planes y políticas tanto externas como internas del SII, llevando a cabo proyectos tendientes a desarrollar un ambiente laboral basado en el respeto, la confianza, reconocimiento y colaboración mutua, y que promuevan la motivación y el compromiso de los funcionarios frente a los objetivos y metas organizacionales. Así también, se desarrollan acciones que se orientan a promover el bienestar y calidad de vida de los funcionarios y de sus familias, y la conciliación de la vida personal-trabajo-familia. 
Las características señaladas promueven un ambiente laboral idóneo y debiesen influir, en la percepción que tienen los funcionarios sobre el Clima Laboral. Por esta razón, es necesario recopilar la opinión de los funcionarios, a través de evaluaciones periódicas y de otras instancias que se describen más adelante.

\subsubsection{Gestión de Clima Laboral}

En el SII se gestiona el Clima Laboral, para impactar en el compromiso y motivación de las personas, lo que favorece desempeños de excelencia y, por ende, el cumplimiento exitoso de la misión y objetivos institucionales.

Se entenderá el Clima Laboral, como un conjunto de cualidades, atributos o propiedades relativamente permanentes de un ambiente de trabajo, que son percibidas, sentidas o experimentadas por las personas que componen la organización y que influyen sobre su conducta.

En este contexto, desde el año 1999 se realizan estudios de Clima Laboral bianuales y de carácter censal en el SII, presentándose un mejoramiento sostenido de sus resultados en el tiempo.

La Gestión de Clima Laboral en el Servicio, se traduce en un proceso continuo que contempla 5 etapas: Encuesta Global, Diagnóstico Nacional y Local, Planes de Clima, Encuesta Abreviada y Ajuste de Planes. Para facilitar este proceso, se establecen estrategias comunicacionales que refuercen el sentido de las intervenciones en Clima, y entender este proceso como una gestión permanente dentro de cada equipo de trabajo.

La última aplicación de la Encuesta de Clima, se realizó en agosto de 2018, en colaboración con la empresa consultora Mide UC de la Pontificia Universidad Católica de Chile, participando el $94 \%$ de los funcionarios. Este estudio, por primera vez, se aplicó a través de un Plataforma Informática.

La encuesta, consta de tres apartados: Clima Organizacional, Supervisión y Calidad de Vida Laboral, compuestos a su vez de dimensiones con sus respectivos reactivos o afirmaciones. Este instrumento se ha modificado ajustándolo, al contexto y los cambios organizacionales.

Con el fin de abordar los resultados obtenidos, se definieron los siguientes ámbitos de acción:

- Planes Transversales: Corresponde al plan de mejoramiento elaborado por la Subdirección de Desarrollo de Personas, en base a los resultados globales del SII, y se implementa a nivel nacional. Para la confección de este Plan se considera la estrategia, objetivos y proyectos del Servicio, además de la disminución de brechas y reforzamiento de fortalezas identificadas. 
- Compromisos Locales: Corresponde a los planes de mejoramiento elaborados por el equipo directivo de cada repartición del SII, esto es, Subdirecciones, Direcciones Regionales y Dirección de Grandes Contribuyentes, considerando las propuestas de los funcionarios levantadas en la etapa de difusión de resultados locales.

Estos Planes representan el eje central de la gestión de Clima, ya que son las palancas que ayudarán a modificar las percepciones de los funcionarios, mejorando su compromiso y desempeño.

A partir del año 2017, la implementación del Plan Transversal se incorporó en el Convenio de Desempeño Colectivo del SII, documento compuesto por compromisos establecidos anualmente con el Ministerio de Hacienda.

Este trabajo sistemático es una oportunidad para que las jefaturas desplieguen sus habilidades de liderazgo y, en consecuencia, puedan gestionar de manera integral el desempeño de sus colaboradores, contribuyendo al cumplimiento de las metas del equipo y las institucionales. Para llevar a cabo este desafío cuentan con el acompañamiento, tanto técnico como metodológico, del Departamento de Desarrollo Organizacional.

\subsubsection{Gestión de las Relaciones Laborales}

La Gestión de las Relaciones Laborales en el SII se ha abordado desde diferentes ámbitos, siendo las Mesas de Trabajo Regionales una de las instancias que se ha desarrollado e institucionalizado en la organización. Son un punto de encuentro que se basa en la participación, el diálogo, la cooperación, la coordinación y la confianza entre las partes, entre otros principios unificadores.

En este contexto, desde el año 2007 se han instalado en las 20 Direcciones Regionales, en la Dirección de Grandes Contribuyentes (DGC), y en la Dirección Nacional.

Las Mesas de Trabajo Regionales y DGC están conformadas por miembros del Equipo Directivo de cada Dirección Regional, Dirigentes Regionales de las Asociaciones de Funcionarios AFIICH y ANEIICH, y el Consultor de Desarrollo Organizacional respectivo, profesional de la Subdirección de Desarrollo de Personas a cargo de asesorar el trabajo de la Mesa.

La Mesa de Trabajo de la Dirección Nacional (DN), está conformada por los Jefes de Departamentos de Gestión de las Personas, Desarrollo Organizacional, un profesional de la Subdirección Desarrollo de Personas y las Directivas de las Asociaciones de Funcionarios ANEIICH y AFIICH de la DN.

La Subdirección de Desarrollo de Personas, tiene como rol el apoyar la gestión de las Mesas de Trabajo, realizando seguimiento y retroalimentación del funcionamiento de éstas, y facilitando la resolución de temas que se presentan en ella. 
En el marco del mejoramiento continuo y ante la necesidad de ir orientando la gestión de las Mesas de Trabajo hacia una mirada más estratégica, la Subdirección de Desarrollo de Personas ha desarrollado diversas acciones:

a) Mejoras e innovación al proceso de funcionamiento de las Mesas de Trabajo: Se desarrolló una Plataforma Informática que permite administrar la información y mejorar la eficiencia del proceso de generación, validación y seguimiento de las actas. Además, se estableció un nuevo Protocolo de Funcionamiento para las Mesas de Trabajo, estableciendo responsabilidades, plazos, funciones y procedimiento de uso de la Plataforma.

b) Fortalecimiento del manejo de información: Se generaron reportes que incorporan categorías y seguimientos de los temas tratados en las Mesas de Trabajo. Además, se publicó una página web de las Mesas de Trabajo en la Intranet del SII, desde el cual se puede descargar información referente a sus principales características, el protocolo de funcionamiento y un acceso directo a la Plataforma Informática.

c) Generación de indicadores de funcionamiento de las Mesas de Trabajo Regionales: En el año 2010, se incorporó un indicador de diálogo institucional en el Balanced ScoreCard del Servicio, conformado por dos subindicadores: frecuencia de las reuniones y eficiencia en el cierre de temas. A partir del año 2016, se incorporaron al Convenio de Desempeño Colectivo, manteniendo los dos subindicadores de frecuencia y eficiencia.

d) Actividades de Formación: Se realizó entre los años 2012 y 2014 un Plan de Formación y una metodología de retroalimentación del desempeño para sus integrantes. Posteriormente, durante los años 2017-2018, se implementaron talleres de Mejoramiento de la Gestión con el fin de entregar herramientas para una gestión más eficiente y eficaz.

El propósito final de este modelo de funcionamiento es potenciar a las Mesas de Trabajo como una instancia de gestión efectiva, no sólo de información, sino que, además, permita la resolución de problemas locales, anticipándose y levantando temas, evidenciando buenas prácticas, coordinando el trabajo, de manera de contribuir a la generación de Ambientes Laborales positivos que faciliten la consecución de los objetivos institucionales.

\subsubsection{Fortalecimiento del Bienestar Social y la Calidad de Vida}

La gestión del Bienestar en el SII, fue recogiendo desde distintos ámbitos, la mirada, sugerencias y expectativas acerca de cambios y mejoras en beneficio de sus afiliados y familias. La encuesta de percepción de calidad de servicios y beneficios a los afiliados y un benchmarking con otros Servicios de Bienestar Públicos, junto al análisis institucional y nuevos desafíos en la gestión de Personas en el SII, impulsaron la reflexión acerca de los ejes centrales de trabajo y las modificaciones que se requerían para el fortalecimiento del Bienestar Social y la Calidad de Vida del Funcionario SII. 
De esta forma se lleva a cabo un proyecto que tiene por objeto fortalecer el Bienestar Social y la Calidad de Vida del Funcionario SII, en los distintos ámbitos de su vida personal y familiar, respondiendo a sus expectativas y necesidades actuales y a los desafíos que enfrenta la Subdirección de Desarrollo de Personas del SII, para contribuir a los ambientes laborales y logro de los objetivos institucionales.

Este proyecto consistió en el diseño e implementación de un nuevo Modelo de la Gestión de Bienestar, que incorpora 3 ejes principales de gestión: Apoyo y Asesoría Social; Beneficios; y Espacios de Encuentro y Orientación, con sus correspondientes líneas de acción.

\section{Imagen $\mathrm{N}^{\circ}$ 4: Modelo de Bienestar y Calidad de Vida SII}

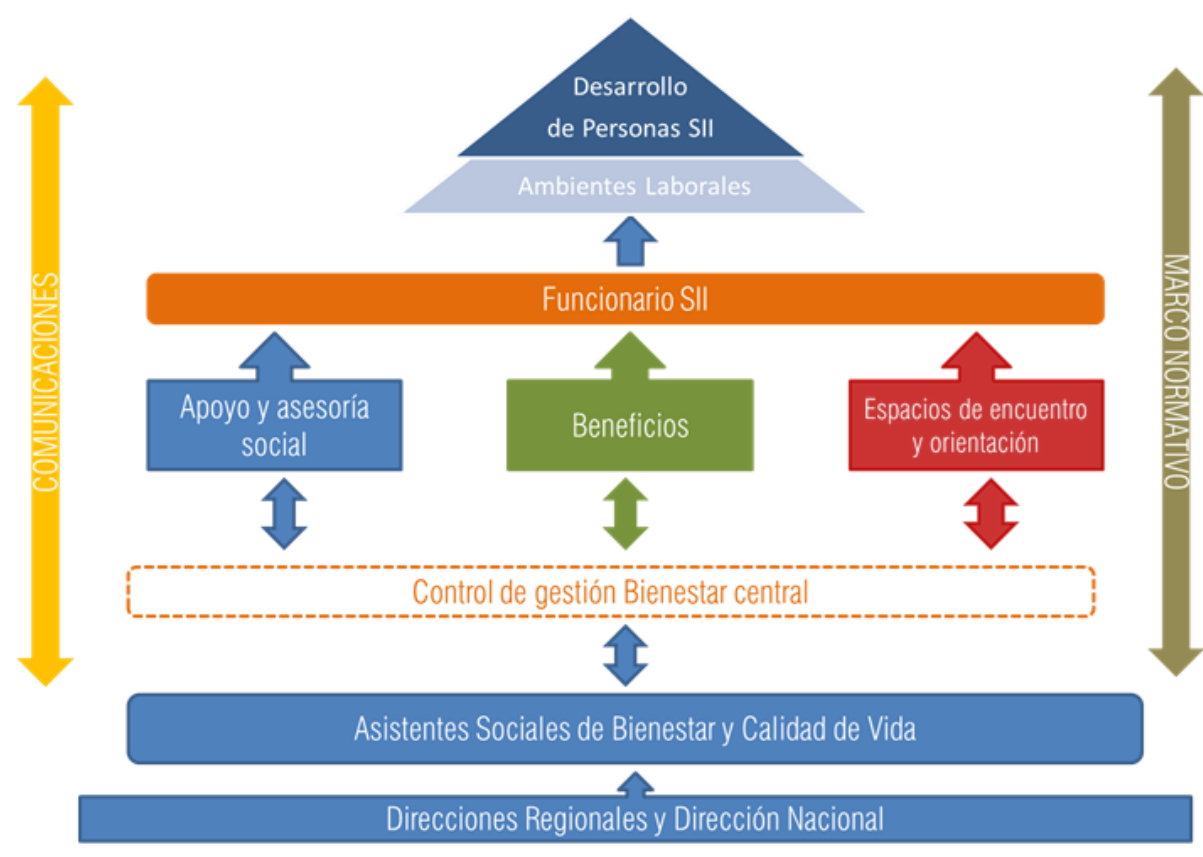

Fuente: Servicio de Impuestos Internos, 2016

\section{a) Apoyo y asesoría social}

Se define como el centro del quehacer del Bienestar, relevándolo como el principal servicio para todos los funcionarios, con foco en la atención de situaciones complejas, que exige gestionar con calidad, proactividad y oportunidad los requerimientos de orientación y apoyo por parte de los funcionarios. Esto implicó reevaluar y alinear a nivel Regional el rol del asistente social, entendiendo que constituye un elemento distintito y de gran valor contar con una red de asistentes sociales, existentes en todas las Direcciones Regionales del país, Dirección Nacional y Dirección de Grandes Contribuyentes. Como resultados se puede destacar: 
- La actualización del perfil y rol de los asistentes sociales de Bienestar.

- Creación de una Plataforma Informática para facilitar el alineamiento del equipo en términos de procedimientos e instrucciones y reportabilidad en un nuevo sistema, de indicadores de gestión regional. Se logró establecer como práctica regular el envío de reportes mensuales, los que permiten identificar las áreas centrales de trabajo con las personas. El cumplimiento de reportabilidad a diciembre de 2018 fue de un 99\%. Además, el sistema de reportes facilitó la mirada sobre la importancia de continuar trabajando en alinear a las Direcciones Regionales respecto al rol definido para los asistentes sociales, en cuanto a su función prioritaria, que es la asesoría y apoyo social.

- Respondiendo a los cambios sociales, se dio énfasis al trabajo con el segmento de afiliados jubilados, consolidando una base de datos, con el objeto de facilitar la comunicación y cercanía.

- Se trabajó en la revisión y diseño de procedimientos internos de trabajo, en temáticas de mayor complejidad, con el objetivo de hacer más eficiente los procesos, contar con estándares de atención y minimizar errores.

\section{b) Beneficios}

Parte esencial de la función del Bienestar. La mejora en este eje apunta a contar con alternativas de "protección" a los afiliados, facilitar la tramitación de beneficios por parte de los funcionarios, innovar y velar por la calidad, y establecer canales de comunicación permanentes con los funcionarios. Se destacan como resultados:

- La generación de nuevos beneficios como la cobertura catastrófica de salud, seguro de vida, y la incorporación de los afiliados jubilados al seguro complementario de salud, lo que entrega una mayor protección a este segmento y condiciones de equidad respecto a los beneficios de los afiliados activos.

- Mejora de beneficios en términos de cobertura y ampliación de beneficiarios.

- Facilitación de trámites como el sistema de pago automático de cuentas (PAC), destinado al segmento jubilados para el pago de sus compromisos con Bienestar.

- Se trabajó en la línea de optimizar las comunicaciones, realizando cambios en el portal de Bienestar, enfocados en dar mayor claridad respecto de los beneficios más demandados, y se diseñó un informativo con temas de interés en un formato sencillo y amigable.

- Como estrategia para conocer la opinión de los afiliados, manteniendo un sistema de medición en el tiempo, se aplicó una encuesta de percepción de calidad de servicios y beneficios a nivel nacional, y se establecieron focos de trabajo en los ámbitos considerados prioritarios, para responder a los desafíos actuales. Esta entregó información relevante para la evaluación de la gestión, planificación y toma de decisiones.

- Un proceso de envergadura fue la revisión y análisis de los cambios normativos para la sala cuna y jardín infantil institucional, que derivaron en el diseño de un Reglamento 
Interno y otras adecuaciones necesarias para dar cumplimiento a las nuevas exigencias que rigen la entrega de este servicio.

c) Espacios de encuentro y orientación para funcionarios y familias

Las acciones que realiza la Oficina de Bienestar, contribuyen a los ambientes laborales, al clima, mayor cercanía en los equipos de trabajo, y la conciliación trabajo-familia. En este sentido, la generación de espacios de encuentro en el espacio laboral, fuera de este y con las familias, contribuirá a la motivación y sentido de pertenencia institucional. En términos de resultados se pueden mencionar:

- Definición de planes anuales de trabajo, acorde al modelo y los nuevos desafíos en materia de Gestión de Personas.

- Definición de temas transversales de orientación y apoyo a los funcionarios y familias, en el ámbito de la conciliación y calidad de vida, con implementación regional.

- Desarrollo de instancias de orientación y apoyo psicosocial, con grupos focalizados (padres con hijos con discapacidad, funcionarios a cargo del cuidado de familiares no valentes, funcionarios próximos a jubilar, afiliados jubilados)

- Diseño de un Programa Anual de Calidad de Vida y Ambientes Laborales.

- Diseño de Protocolo para la atención de casos de consumo problemático de alcohol y drogas.

- Diseño e implementación de Protocolo de Inclusión Laboral, sobre la base de la nueva normativa, difusión y sensibilización en esta temática.

\subsubsection{Instructivo Presidencial y Buenas Prácticas Laborales}

Las orientaciones del Instructivo Presidencial sobre Buenas Prácticas Laborales en Desarrollo de Personas en el Estado se tradujeron en un trabajo conjunto entre la Subdirección de Desarrollo de Personas, la Oficina de Comunicaciones Corporativas y las Directivas Nacionales de las Asociaciones de Funcionarios, ANEIICH y AFIICH, que tuvo como resultado el diseño de un Plan Trienal 2015-2018 del SII. Cabe señalar que cada institución pública debió elaborar este plan de trabajo, remitiéndolo para su conocimiento, revisión y seguimiento a la Dirección Nacional del Servicio Civil.

Posteriormente al cumplimiento del Plan Trienal, cabe recordar, y tal como se ha mencionado, la Dirección Nacional del Servicio Civil se transforma en una entidad rectora, publicando las Normas de Aplicación General en Gestión y Desarrollo de Personas.

La Subdirección de Desarrollo de Personas, a través de un trabajo conjunto entre sus equipos, desarrolla el Sistema de Mejores Prácticas Laborales y el Plan de Gestión del Primer y Segundo Grupo de Normas de la DNSC que, entre otros, responde y da cumplimiento a los compromisos requeridos por la Dirección Nacional del Servicio Civil. 
El Sistema de Mejores Prácticas Laborales abarca principalmente dos ámbitos, el primero guarda relación con la sistematización y difusión de aquellas normativas y políticas que el SII ya realiza y que se enmarcan dentro de buenas prácticas. Y el segundo, corresponde al levantamiento y sistematización de aquellas mejores prácticas tanto internas como externas al SII.

El Plan de Gestión del Primer y Segundo Grupo de Normas de la DNSC, consiste en la articulación de una red de trabajo al interior de la Subdirección, donde cada representante tiene la responsabilidad de gestionar dentro de su equipo, los contenidos requeridos, en vías de un proceso de implementación acorde a la realidad del SII, sus necesidades y las mejores prácticas laborales.

A través de esta planificación, se han ido materializando mejores prácticas laborales, que constituyen una piedra angular en la gestión de personas, dada su transversalidad y presencia en todos los ámbitos del ciclo de vida laboral, vinculándose al ingreso, gestión del desempeño, capacitación, movilidad, egreso, entre otros, siendo integrados en la Política de Desarrollo de Personas del SII

El Plan Trienal y las Normas de Aplicación General, se han traducido en el diseño e implementación de productos concretos como políticas, procedimientos, protocolos y programas de trabajo, logrando el $100 \%$ de cumplimiento de estos compromisos. Entre otros productos, pueden mencionarse los siguientes:

1. Política de Desarrollo de Personas

2. Procedimiento de Inducción de funcionarios que ingresan al SII

3. Procedimiento Institucional ante la denuncia y sanción de Maltrato Laboral, Acoso Laboral y Acoso Sexual

4. Protocolo institucional para la Conciliación entre la Vida Laboral, Vida Familiar y Vida Personal

5. Política Institucional para el Ejercicio del Liderazgo por parte de las Jefaturas

6. Política de Prevención de Riesgos y Salud Ocupacional

7. Procedimiento de Carrera Funcionaria para el escalafón Profesional

8. Procedimiento de Carrera Funcionaria para los escalafones Fiscalizadores, Técnicos, Administrativos y Auxiliares

9. Procedimiento de Ingreso de Personas a la Contrata, Suplencia y Honorarios

10. Procedimiento para Jefaturas de Cuarto Nivel Jerárquico y Jefaturas De Oficina

11. Procedimiento para la Formación y Capacitación 
12. Procedimiento del Programa de Expertos y Especialistas

13. Procedimiento sobre el Egreso de Personas

14. Protocolo de Reconocimiento a los funcionarios y funcionarias del SII

15. Protocolo para el ejercicio del derecho sala cuna para funcionarias y funcionarios públicos

16. Reglamento de Uso del Derecho a Sala Cuna y Beneficio de Jardín Infantil en el SII

17. Procedimiento de Uso de las Cabañas de Lican Ray.

18. Protocolo para la reintegración al cargo luego de licencias prolongadas.

19. Política de Vestuario Semiformal durante el periodo estival

\subsection{Eje Carrera y Formación}

\subsubsection{Ingreso y Carrera}

\section{a) Aspectos Generales}

Las nuevas metas y exigencias que trajo consigo la Reforma Tributaria para el Servicio de Impuestos Internos, desencadenaron la necesidad de materializar las condiciones para que la institución afrontara sus compromisos y fortaleciera sus niveles de profesionalismo, eficiencia, probidad y transparencia en el ejercicio de su función pública.

Con la participación e involucramiento de sus funcionarios, en 2014 se comenzaron a discutir las bases de una ley de fortalecimiento institucional. Se hizo a través de una mesa de trabajo que contó con la participación de representantes de la Subsecretaría de Hacienda, la Dirección del Servicio de Impuestos Internos, la Asociación de Fiscalizadores del SII (AFIICH) y la Asociación Nacional de Empleados del SII (ANEIICH).

Este debate participativo y colaborativo se plasmó en un Protocolo de Acuerdo, firmado el 27 de enero de 2015 por los distintos actores institucionales involucrados, que sería el punto de partida para generar la Ley de Fortalecimiento Institucional y, a través de ella, contribuir con el cumplimiento de las metas inmediatas y de futuro de la Reforma Tributaria.

En efecto, en sus páginas introductorias el Protocolo estableció que "se ha planteado un ambicioso plan que impulse un nuevo ciclo de Modernización del SII, el que en acuerdo con todos los actores relevantes de la organización, se materializará en un proyecto de ley otros instrumentos normativos, que incluirán aspectos tales como el aumento de la dotación, el fortalecimiento de la carrera funcionaria en todo el ciclo laboral y en todos los escalafones de la institución, la racionalización de las remuneraciones, reduciendo la variabilidad de las mismas, la actualización y modernización de las condiciones de ingreso, el mejoramiento de la organización funcional del SII, entre otros”. 
Cabe señalar que, a través de este proceso de diálogo, con la participación activa de las distintas partes, se logró conjugar los diversos intereses involucrados.

La Dirección del SII se concentró en aumentar las capacidades fiscalizadoras de la institución mediante un incremento de la dotación, la creación de una estructura que se dedicara a la atención y asistencia al contribuyente, así como también en la modernización de la Ley de Planta para contribuir al desarrollo de carrera de los funcionarios al interior de la Institución.

Por su parte, las asociaciones de funcionarios estuvieron decididamente alineadas con los objetivos institucionales antes expuestos $\mathrm{y}$, adicionalmente, comprometidos con el desarrollo de carrera, buscando además mejorar las condiciones salariales de sus representados. En este sentido, gran parte de la discusión se concentró en el desarrollo de carrera de todos los estamentos: Auxiliares, Administrativos, Técnicos, Profesionales y Fiscalizadores.

En tanto, la Dirección de Presupuestos buscó generar un equilibrio entre la inyección de recursos aprobados para el SII, con el objeto de apoyar su proceso de modernización y mejoramiento, con el necesario aseguramiento de una implementación exitosa de los objetivos de la Reforma Tributaria; considerando además que la Ley de Fortalecimiento del SII podría servir de modelo para otras instituciones de la administración pública.

Este Protocolo de Acuerdo, basado en la participación e involucramiento de los distintos actores institucionales y gremiales, serviría como insumo esencial para la posterior discusión y dictación de la Ley de Fortalecimiento Institucional del SII y el desarrollo de carrera, en sus distintas variantes al considerar todo el ciclo de vida funcionaria, desde el ingreso, desarrollo, hasta el egreso.

Tras este proceso, la Ley $\mathrm{N}^{\circ} 20.853$, de Fortalecimiento Institucional y Modernización del SII, fue publicada en el Diario Oficial, con lo que entró también en vigencia, el 8 de Julio de 2015. Dicho cuerpo legal establece modificaciones tanto en el ámbito del ingreso y la promoción de los funcionarios, como en la estructura de remuneraciones.

\section{b) Ingreso}

La Ley de Fortalecimiento Institucional implanta un mecanismo único en la administración pública chilena, que es reconocer la trayectoria de los funcionarios contrata del propio Servicio y hacerles elegibles de manera exclusiva para ingresar a la planta institucional (antes de ello, el ingreso a la planta se realizaba por concursos públicos en los cuales no se reconocía a los funcionarios que ya trabajaban en el Servicio en calidad de contrata, quienes tenían que competir en igualdad de condiciones con los postulantes externos, en circunstancias que ya poseían un capital de conocimiento y experiencia en la institución). 
Para la implementación de este mecanismo, la Ley de Fortalecimiento plantea como condición que todo funcionario que ingresa a la contrata y se hace elegible de manera exclusiva para acceder a la planta institucional, debe ingresar al Servicio a través de un concurso abierto en donde la evaluación de sus méritos personales y laborales constituyen el valor central.

Por ello, los procesos de ingreso al Servicio se han visto fortalecidos a través de varios elementos:

- Carácter legal del llamado a concurso.

- Protocolización de los mecanismos de difusión de los procesos concursales (sitio web del SII, portal de empleos públicos, diarios de circulación nacional).

- Reglamento específico de ingreso a la contrata del SII.

- Nuevos y actualizados perfiles de competencias para todos los cargos de ingreso.

- Aplicación de entrevistas técnicas protocolizadas a fin de evaluar las capacidades técnicas y formativas de los postulantes.

- Aplicación de evaluaciones psicolaborales a fin de evaluar la presencia de las competencias laborales definidas en el perfil del cargo, así como los aspectos valóricos requeridos para ingresar al Servicio.

En consecuencia, la carrera funcionaria en el SII se inicia al ingresar a cargos en la contrata a través de concursos regulados y abiertos, donde se pone un especial énfasis en los aspectos técnicos, valóricos y competencias laborales específicas.

\section{c) Promoción}

En el ámbito de la carrera funcionaria, se fortalecen los mecanismos de promoción en todas las plantas del SII, disponiendo que la promoción en las plantas de fiscalizadores y de técnicos se efectuará por concurso interno, y por ascenso en las plantas de administrativos y de auxiliares. En el caso de la provisión de los cargos de la planta de profesionales, se efectuará mediante concursos internos en los cuales no solo podrán participar funcionarios de planta, sino que también aquellos adscritos a la calidad jurídica de contrata. Del mismo modo, se establecen reglas y mecanismos para la movilidad entre estamentos, cuando funcionarios de un estamento adquieren requisitos para poder avanzar a otro y así dar continuidad a su carrera.

Para reglar estos nuevos mecanismos, además de algunos aspectos que se incluyeron en la Ley de Fortalecimiento, se emitieron dos reglamentos internos, que abordan los mecanismos de Desarrollo de Carrera de los Estamentos Auxiliar, Administrativos, Técnicos y Fiscalizadores, el primero, y el mecanismo de Desarrollo de Carrera del Estamento Profesional, el segundo.

d) Encasillamiento en la Nueva Planta del SII 
Reconocimiento a la carrera funcionaria: Al ampliarse las nuevas plantas del SII, también se establece, de manera excepcional, la manera en que éstas puedan ser completadas, dando prioridad para ello a los propios funcionarios del SII.

Se trata de un proceso de encasillamiento, a través del cual se ocupan las plantas recientemente creadas, constituyéndose en un mecanismo de reconocimiento de la carrera funcionaria, al darles a los propios funcionarios, ya sean de planta o contrata, la exclusividad en su participación.

En este orden, se establecieron reglas y un cronograma según estamento. En el caso del Profesional, se consideraron dos fases, siendo la primera en 2016 y la segunda en 2017. Para el Fiscalizador el desarrollo del encasillamiento se programó para tres años, comenzando en 2016, siguiendo en 2017 y finalizando en 2018. En el caso de los estamentos Técnico, Administrativo y Auxiliar, se desarrolló durante el año 2016.

A partir de las herramientas legales que proveyó la Ley de Fortalecimiento del SII y el posterior Decreto con Fuerza de Ley $\mathrm{N}^{\circ}$ 1, que fija la nueva planta de personal, en 2016 se han ido implementando gradualmente concursos que han contribuido a modernizar el desarrollo de carrera de los distintos estamentos de funcionarios.

e) Concurso de movilidad en la contrata del estamento profesional

\section{Modelo de Áreas Funcionales:}

Antes de producirse el encasillamiento en la planta de profesionales, se decidió realizar un concurso de movilidad en la contrata. A través de él, los funcionarios del estamento Profesional tuvieron una significativa oportunidad de desarrollo de carrera, pudiendo aumentar de grado en la contrata en conformidad a los requisitos y procedimiento de postulación. El objetivo de este proceso fue estructurar el estamento Profesional en cuatro áreas funcionales y, con ello, prepararlo para el posterior proceso de encasillamiento, de forma de diseñar un modelo de carrera por áreas funcionales.

Las áreas funcionales fueron definidas sobre la base de las tareas asociadas a los ámbitos de desempeño de los profesionales del SII:

Área Jurídica, Normativa y Legal Tributaria: Integrada por profesionales cuyo desempeño esté dirigido al desarrollo de funciones orientadas a prestar apoyo normativo y legal a la institución en el ámbito tributario.

Área de Fiscalización, Avaluaciones y Asistencia: Integrada por profesionales cuyo desempeño se encuentre asociado al diseño, coordinación y ejecución de procesos centrales de la institución en materias de fiscalización, avaluaciones y asistencia a los contribuyentes.

Área de Gestión: Integrada por profesionales (incluye los abogados pertenecientes a las áreas mencionadas en este punto, salvo que se diga expresamente lo contrario) cuyo 
desempeño se encuentre dirigido al desarrollo de funciones orientadas a la gestión institucional, coordinación y supervisión general de personas, apoyo a los procesos institucionales, administrativos y comunicaciones corporativas.

Área Informática: Integrada por funcionarios cuyo desempeño se encuentre dirigido al desarrollo y operación de sistemas informáticos de apoyo u operación institucional.

Cabe señalar que fue la primera vez que se realizó un proceso masivo de movilidad, dirigido al estamento profesional completo y por unidades de desempeño diferenciadas.

f) Jefes de Unidad al Tercer Nivel Jerárquico: En el proceso de negociación de la Ley de Fortalecimiento Institucional y en su posterior implementación se concretó el aumento de planta directiva del SII en 55 cargos de Tercer Nivel Jerárquico, que se rigen por normas especiales en su provisión, mantención y dejación del cargo, incorporándose a la carrera funcionaria. Deben ser provistos mediante concurso cerrado para funcionarios públicos, con el debido cumplimiento de requisitos. Sólo se abre para toda la ciudadanía cuando se ha declarado desierto por falta de postulantes idóneos. Su ejercicio dura tres años, en la medida que el funcionario se mantiene en la lista 1 de calificación. Tras ello, por decisión de la autoridad del servicio que corresponda, puede prorrogarse el nombramiento por una sola vez por tres años adicionales. Al término de ese período, estos cargos deben volverse a concursar.

Con el mencionado aumento de la planta directiva se incorpora a ésta a los jefes de unidad, que corresponden a las oficinas del SII ubicadas jurisdiccionalmente en las Direcciones Regionales del país, permitiendo al mismo tiempo que amplíen su desarrollo de carrera.

En efecto, se ha concursado progresivamente todas las unidades del país, ofreciendo a los postulantes un modelo de selección más exigente y, a la vez, más atractivo. Esto derivó en un aumento de la cantidad de postulantes y en una mejora del proceso de selección.

g) Implementación Cuarto Nivel Jerárquico: Al momento de comenzar con la implementación de la Ley de Fortalecimiento se fueron detectando algunos aspectos que era necesario resolver en materia de estructura.

A nivel de Dirección Nacional del SII existían criterios homogéneos de ordenamiento sólo hasta los niveles de jefes de departamentos, que corresponde al Tercer Nivel Jerárquico. Bajo la dependencia de éstos, existían unidades organizativas creadas con criterios disímiles, con provisión de cargos de jefatura desde nominación directa hasta procesos de selección interna y sin incentivo pecuniario para el ejercicio de las tareas de supervisión.

En algunos casos, por necesidades de gestión, existían estructuras equivalentes a un Quinto Nivel Jerárquico, con distintas dependencias y nombres de las estructuras de un mismo nivel que inducían a confusión. 
Si bien esta estructura, con jefaturas denominadas informales, nació a la luz de necesidades de una mejor organización del trabajo y gestión institucional, no respondía al proceso de modernización que se empezaba a fraguar con la implementación de la Ley de Fortalecimiento Institucional.

Se definió un Cuarto Nivel Jerárquico, entregando recursos permanentes en materia de asignación de supervisión. Para acceder a ello, previamente estas jefaturas tenían que cumplir requisitos como poseer una estructura creada formalmente, una jefatura provista por concurso interno y contar con un número mínimo de supervisados. Así, antes de pasar a la puesta en marcha del Cuarto Nivel Jerárquico, el SII hizo una revisión completa de la estructura de la Dirección Nacional y se instruyó realizar los cambios necesarios, no sólo en términos de estructura, sino que también ajustando los objetivos de cada Subdirección y los ámbitos de responsabilidades y funciones. Este proceso significó una fructífera discusión en los equipos directivos, que se tradujo en delimitación de funciones y en el nacimiento de una estructura más eficiente, acorde a los nuevos desafíos institucionales.

En el primer semestre del 2016 se generaron los cambios en las once Subdirecciones de la Dirección Nacional. Con esto concluido, se daba inicio a los procesos que significarían la implementación de la nueva estructura, la provisión de cargo y el acceso al derecho a percibir asignación de supervisión en el Cuarto Nivel Jerárquico de la Dirección Nacional.

h) Regulación Procesos de Desarrollo de Carrera: Reglamentos: A partir de los cambios introducidos por la Ley de Fortalecimiento Institucional y la publicación de la nueva Ley del Planta del SII, fue necesario reformular las políticas y procedimientos de desarrollo de carrera.

El cambio trascendental en la manera de ingresar a la planta del SII constituyó la mayor innovación en el desarrollo de carrera en la administración pública chilena, ya que se definió legalmente que la provisión de los cargos de planta se realizaría estrictamente a través de postulantes de la contrata ingresados originalmente mediante concurso abierto. Esto llevó a la administración del SII a definir una serie de Reglamentos de Desarrollo de Carrera, según cada escalafón.

Es así como se publicó la Resolución, que fijó el Reglamento de Desarrollo de Carrera para los estamentos Fiscalizador, Técnico y Auxiliar. Se definió de esta manera, la carrera en lo específico del ingreso a la contrata, ingreso a la planta y movimientos al interior de ella según el estamento. Así, en los estamentos Auxiliar y Administrativo mediante ascensos automáticos según vacancias de los cargos, mientras que en el estamento Técnico y Fiscalizador a través de procesos concursales de promoción. Adicionalmente, en este reglamento se definió el ingreso desde un estamento a otro, con reglas internas claras.

Del mismo modo, en todos los estamentos se definieron pruebas de selección en materias técnicas, de habilidades, psicolaborales y entrevistas presenciales. En el estamento 
Fiscalizador y Técnico se incorporó, además, la aprobación de un curso técnico interno como parte del proceso de selección.

Para el estamento Profesional se realizó un segundo reglamento especial de desarrollo de carrera, de acuerdo a las funciones desempeñadas o áreas funcionales: Fiscalización, Asistencia y Avaluaciones; Informática; Gestión; y Jurídico Normativa. La particularidad de este reglamento es que para obtener movilidad al interior de la planta se realizarán procesos de ingresos a los distintos grados que quedan vacantes, compitiendo por ingresar a dicho grado los funcionarios de la contrata, así como aquellos que se ubican en grados inferiores en la planta.

Adicionalmente, dado que la Ley de Fortalecimiento Institucional del SII definió las bases para la creación de un Cuarto Nivel Jerárquico, que corresponde a jefaturas de grupo y de áreas, fue necesario reglamentar la carrera funcionaria en el acceso, mantención y salida de dichos cargos. Se elaboró de esta manera un tercer reglamento para este nivel: el Reglamento de Jefaturas del Cuarto Nivel Jerárquico y Jefaturas de Oficina.

i) Estructura de Remuneraciones: Uno de los aspectos centrales del desarrollo y reconocimiento de carrera es la estructura de remuneraciones.

Dispone una reestructuración de las remuneraciones, para lo cual se modifican los componentes de la asignación especial de estímulo por desempeño en el cumplimiento de metas: la parte variable estará asociada al cumplimiento de metas vinculadas a la reducción de la evasión y elusión tributaria, incluyendo indicadores de fiscalización y facilitación en el cumplimiento tributario, lo que se materializará en el Convenio de Desempeño Colectivo; mientras que el componente por cumplimiento de meta institucional de disminución de la evasión se transforma en uno asociado a la gestión tributaria, fijo y de pago mensual.

Reemplaza la bonificación anual ligada a la calidad del servicio prestado a usuarios y contribuyentes por una bonificación especial que se pagará mensualmente.

Establece un bono por experiencia calificada de apoyo a la gestión tributaria, que se pagará mensualmente, al personal titular de cargos de las plantas de técnicos, de administrativos y de auxiliares, cuando cumplan diez años de servicio en el grado tope de la respectiva planta.

j) Mejoramiento Continuo: Desde la entrada en vigencia de la Ley de Reforma Tributaria, Ley 20.780, el año 2014 y todos los cuerpos legales y reglamentarios derivados de la misma, la Ley de Fortalecimiento Institucional, los Reglamentos Internos, la Ley de Planta; se logró la plena implementación de un nuevo Modelo de Desarrollo de Carrera en el Servicio de Impuestos Internos. 
Estos últimos tres años han significado dar estabilidad a un sistema, se ha generado certeza en los directivos y funcionarios respecto de prácticas, políticas y procedimientos, lo que se ha reconocido como un patrimonio de la gestión interna, en materia de personas.

De la misma forma, ha permitido observar en el tiempo las fortalezas del diseño en su implementación práctica, así como espacios de posible mejora. A partir de ello, durante el último bimestre del año 2018 surgió la iniciativa de revisar específicamente la forma y fondo de las definiciones internas en los procesos de selección de jefaturas, tanto del tercer nivel como del cuarto nivel jerárquico. Para ello se definió un equipo interno multitarea con apoyo de una consultora externa, para revisar y generar propuestas de mejora. Esta iniciativa se enmarca en el Eje 4 del Plan Estratégico Institucional, Ética y Prácticas Laborales, específicamente en materia de Liderazgo Institucional.

\subsubsection{Formación}

a) Aspectos generales: En los capítulos anteriores hemos revisado aspectos que constituyen las bases de un Modelo de Gestión de Personas que propende al desarrollo integral de éstas, a través de un sistema que involucra las distintas etapas de la vida funcionaria.

Este modelo considera procesos y ciclos en los cuales se explicitan requisitos y exigencias de ingreso, permanencia y ascenso en una carrera funcionaria; los incentivos, evaluaciones y retribuciones que median; así como las condiciones del ambiente que sirve de escenario y entorno.

No obstante, no se trata de un modelo que se explica desde lo estático, sino que se comprende dinámico, no en cuanto a su condición y estructura, sino que a lo que produce y genera. Es aquí donde el proceso de formación toma sentido como uno de los componentes esenciales de este modelo de gestión de personas.

La adquisición y desarrollo constante y sistemático de conocimientos y competencias, en aras de alcanzar un desarrollo laboral que permita a los funcionarios del SII otorgar un servicio de excelencia, considerando las necesidades de mayor eficiencia y eficacia en los procesos de fiscalización que demanda la Reforma Tributaria, junto con el cumplimiento de los estándares de calidad en la atención a los contribuyentes; exigen esfuerzos continuos, sistemáticos, en el proceso de formación y capacitación.

Una mejor preparación y entrenamiento en materias técnico-tributarias, utilización de herramientas informáticas, así como el desarrollo de habilidades relacionales y el manejo de conocimientos actualizados, contribuyen a una mejor labor funcionaria y permiten configurar un servicio de calidad que facilita el cumplimiento de las metas institucionales.

En definitiva, la formación y capacitación así entendidas generan las condiciones humanas y organizacionales necesarias para la consecución de los objetivos institucionales. Resultan, 
por eso, claves también para el desarrollo integral de la vida funcionaria porque se asocian a aprendizaje, oportunidades, desempeño, crecimiento y promoción.

La capacitación opera bajo principios de calidad y no discriminación en el acceso a los distintos programas de aprendizaje, el cual, a su vez, se orienta al mejoramiento del desempeño y desarrollo de habilidades individuales y de equipos de trabajo; con un sentido de efectividad, a través de la participación, relevancia y pertinencia en las acciones de capacitación con transferencia de conocimiento, retroalimentación y evaluación del aprendizaje. De esta forma, se logra constituir la responsabilidad compartida entre los distintos actores que participan en este proceso: funcionarios, jefaturas, Comité Bipartito de Capacitación, Comités Regionales de Capacitación y la Subdirección de Desarrollo de Personas.

La formación en el SII posee distintas funciones interrelacionadas que conforman un proceso integral. El punto de partida de éste es la detección de necesidades de capacitación (DNC) que se relaciona con los propios lineamientos estratégicos de la institución y en la que también inciden las brechas de desempeño que surgen al comparar las competencias de los funcionarios con los respectivos perfiles del cargo.

A estas necesidades responde entonces el diseño del Plan Nacional de Formación y Capacitación, a través del cual se proyectan las acciones a realizar que buscan generar conocimientos y fomentar el desarrollo de habilidades en los funcionarios necesarios para su óptimo desempeño laboral, definiendo un plan trienal y anual a partir de los requerimientos que son relevados por los Comités Regionales de Capacitación y la Dirección Nacional en el proceso de detección de necesidades ya señalado.

Asimismo, en el Plan Regional de Capacitación se incluyen las acciones de formación desarrolladas por el Departamento de Formación en conjunto con las Direcciones Regionales y Dirección de Grandes Contribuyentes para dar respuestas focalizadas y específicas a los requerimientos de capacitación que en éstas se prioricen. La selección e incorporación de estas actividades al plan son competencia del Comité Regional de Capacitación de acuerdo al marco de acción que para estos efectos define el Departamento de Formación.

Por su parte, el Plan de Capacitación Externa contempla un conjunto de acciones de formación requeridas por los funcionarios provistas por organismos externos que responden a necesidades formativas específicas del Servicio. La selección e incorporación de las actividades de formación a este plan anual son de competencia del Comité Regional de Capacitación, en el caso de las Direcciones Regionales, y de las Subdirecciones, en el caso de la Dirección Nacional, de acuerdo al marco de acción definido por el Departamento de Formación.

Finalmente, en los Programas Especiales de Capacitación se incluyen acciones de formación y capacitación específicas determinadas por las características propias de sus 
destinatarios y que responden a diversas necesidades de la institución, en los cuales se incluye, por ejemplo, el Programa de Inducción de Nuevos Funcionarios, Programas de Formación Inicial (Fiscalizadores, Técnicos), el Programa Institucional de Formación Directiva, Programas Emergentes, Cursos asociados a procesos de promoción funcionaria, entre otros.

En el diseño de programas, cursos, talleres o seminarios, tanto las metodologías utilizadas para impartirlos como los materiales educativos que sirven de soporte, son dinámicos, pues requieren de una permanente actualización. Además, pueden dictarse en modalidades presencial, semipresencial o a distancia, a través de la utilización de tecnologías de información y plataformas educativas en línea.

En cuanto al carácter de estos, las acciones de formación internas están a cargo de monitores que, por su trabajo, competencias y formación, alcanzan un dominio experto de las materias que se abordan. Paralelamente, éstos cuentan con el apoyo de asesores metodológicos y de capacitación y la validación técnica de las instancias organizacionales pertinentes. En tanto, los cursos externos son dictados por organismos y/o especialistas que no son parte de la institución.

La formación de monitores es también parte de las acciones de formación y capacitación, pues permite la conformación de cuadros que contribuyen a este proceso, con la ventaja de conocer de primera mano las necesidades institucionales de conocimientos y habilidades que se requieren. Consecuentemente, inciden directamente en el alcance, calidad y eficacia de estas acciones.

El despliegue de la formación y capacitación conlleva entonces, como se desprende de los componentes descritos, de una logística de ejecución vinculada a la programación o calendarización de las actividades, los recursos financieros y materiales que se necesitan, la infraestructura, el presupuesto disponible, los cupos factibles de ofrecer y la coordinación para reunir a los participantes y al equipo humano de monitores.

Como una forma de monitorear y contribuir al necesario dinamismo de las acciones para mejorar, corregir o actualizar, se emplean evaluaciones a distintas dimensiones de la formación. Una de ellas se vincula a la reacción o percepción que tienen los participantes, considerando las condiciones en las que se dictó el curso, su calidad y diseño. La segunda se asocia al aprendizaje logrado, constituido por la adquisición de conocimientos, habilidades y actitudes. La evaluación de transferencia es de más largo aliento, pues se aplica una vez concluida la acción de capacitación, relacionándola con la aplicación práctica en el puesto de trabajo. De acuerdo a los resultados de las distintas evaluaciones, se introducen las mejoras, rediseñando los cursos, ajustando las metodologías, actualizando materiales de aprendizaje y contenidos entregados, entre otros ajustes.

\subsection{Centro de Formación e Investigación Tributaria}


Si bien el proceso de formación y capacitación en el SII es encabezado por el Departamento de Formación, con la coordinación de la Dirección Nacional, las Direcciones Regionales, la Subdirección de Desarrollo de Personas, el Comité Bipartito de Capacitación Nacional y los Comités Regionales de Capacitación, el desafío en esta materia demanda una estrategia mayor $\mathrm{y}$, por ende, una estructura que lo contenga y que facilite el desarrollo de las potencialidades existentes.

En este contexto, la creación del Centro de Formación e Investigación Tributaria surge como el proyecto que reúne y hace factible las aspiraciones de crecimiento y desarrollo del potencial de formación y capacitación del SII, en el marco de entregar un servicio de excelencia que sea un ejemplo para las instituciones que conforman la administración pública, $\mathrm{y}$, en un radio mayor, a las administraciones tributarias de otros países.

En concreto, su objetivo es entregar capacitación y perfeccionamiento especializado a través de la realización de actividades y programas que permiten fortalecer y adquirir nuevos conocimientos a los funcionarios del Servicio, a funcionarios de otras Administraciones Tributarias y de otras instituciones públicas, nacionales o extranjeras. Para ello, puede realizar cursos, talleres, seminarios, congresos, entre otras acciones, fomentado también el desarrollo de iniciativas personales y/o grupales de formación; así como generar, gestionar y coordinar la realización de investigación en materias tributarias que sean de competencia del Servicio.

Mejorar la gestión propia de la capacitación y formación conlleva ampliar el ámbito y marco de acción de este proceso y de quienes inciden en él. Se trata de contar con formadores dedicados a la labor, reconocidos por ella, con oportunidades de desarrollarse y cuya tarea no finalice con la dictación de un programa, curso, taller o seminario.

\section{Conclusiones}

La crucial misión del Servicio de Impuestos Internos (SII) en el proceso de recaudación de recursos por parte del Estado, y la consiguiente disponibilidad de éstos como vía de inversión social para un mejor desarrollo del país, teniendo como fin último el mejoramiento de las condiciones de vida de sus habitantes, especialmente los más necesitados, sitúan a esta institución de la administración pública en el corazón de las transformaciones.

Mejorar los procesos que aumenten la recaudación y equidad tributaria y la disminución de la evasión y elusión, necesariamente trajo desafíos para el SII, como desarrollar una mayor efectividad de la fiscalización, proveer más recursos y fortalecer la administración tributaria, además de mejorar los servicios y la atención a los contribuyentes.

Este nuevo escenario implicó la necesidad de fortalecer a este engranaje central de una recaudación más eficaz y eficiente. Como se revisó en los capítulos de este documento, surge así la necesidad de hacer cambios a la forma en que se gestiona el empleo en el SII. Esto generó que las personas se situaran en el centro de la transformación, 
implementándose un nuevo modelo de gestión que se hiciera cargo de manera integral de su desarrollo.

Se propone para el servicio entonces:

1.- Uno de los factores claves del éxito de esta transformación, fue la visión compartida de desarrollo de personas que tuvieron desde el inicio los diversos actores organizacionales, tales como la Alta Dirección, las Asociaciones de Funcionarios, la Subdirección de Desarrollo de Personas y los propios funcionarios, quienes, desde cada uno de sus roles, aportaron a que este proceso se llevara a cabo.

2.- El modelo de desarrollo de personas, nacido al alero de los nuevos desafíos, y las posteriores definiciones y prioridades estratégicas, implicó cambios en diversos ámbitos relacionados a la vida funcionaria, promoviendo la ejecución de un trabajo con altos grados de especialización, en el que las personas se empoderan de sus roles y funciones, respondiendo con criterios técnicos, construyendo así una institución que apunta a entregar un servicio de excelencia, de cara a la ciudadanía en general, a los contribuyentes y al Estado; siendo fiel a su misión institucional y perfilando su fortaleza y autonomía.

3.- La conformación de liderazgos capaces de llevar a cabo las nuevas exigencias institucionales, con la consecución de los respectivos resultados, ha permitido al mismo tiempo, la conformación de equipos con convicción en el cambio y comprometidos y capacitados para alcanzar las metas. Éstos tienen que desenvolverse en un clima laboral adecuado para el aprovechamiento y desarrollo de las potencialidades individuales que contribuyan a la concreción de objetivos comunes.

4.- El seguir mejorando los procesos de selección, ingreso y desarrollo de carrera basado en reglas transparentes y meritocráticas, apunta a que confluyan capacidades, conocimientos, habilidades y destrezas requeridas para cumplir a cabalidad roles, funciones y tareas. Además, la constante preocupación y entrega de herramientas para formar y capacitar a los funcionarios, fortaleciendo la consolidación de liderazgos y de equipos, proporcionan certezas de calidad y confianza, tanto a nivel interno, en términos de identidad, como externos, relacionados con la imagen institucional.

5.- Tener y comprender el sentido de lo que se hace, el por qué y para qué estamos cambiando, nos ha permitido tener la fuerza, compromiso y convicción de involucrarnos fuertemente con los nuevos desafíos y más aún con nuestra misión institucional. Es en este sentido necesario, crear nuevas maneras de fomentar capacidades para desarrollar este propósito. La gestión de empleo alineada estratégicamente permitirá construir, fomentar y desarrollar las capacidades que la institución requiera. Y es así como la gestión de personas constituye para la gestión moderna, un socio estratégico que es necesario desarrollar.

6.- Este impulso de transformación debe ser permanente, debe ser parte del plan estratégico de la institución y, por sobre todo, debe ser la guía de lo que se puede construir en reglas del juego del empleo en un servicio de excelencia, que necesita y merece de manera permanente y sistemática, crear nuevas capacidades para responder a los desafíos que el país necesita implementar. 
7.- Finalmente, la motivación, el compromiso y dedicación de todos los funcionarios y funcionarias que han aportado a esta transformación, nos hace sentir muy motivados para continuar por esta senda, con nuevos desafíos permanentes, que impacta directamente en la vida profesional y en el desarrollo del Servicio.

\section{Referencias}

Fernandez, I., \& Winter, T. (2003). 2003 - Equipos de alto desempeño: Un gran desafío para las organizaciones. Psicología y Empresa, $4 . \quad 1 \quad$ - 26. https://www.academia.edu/2057867/2003_Equipos_de_alto_desempe\%C3\%B1o_un_gran desaf\%C3\%ADo_para_las_organizaciones

Katzenbach, J. \& Smith, D. (1993). The Wisdom of Teams: Creating the High-performance Organisation, Harvard Business School.

Ley $\mathrm{N}^{\circ} 20.853$ de 2015. Fortalece al Servicio de Impuestos Internos para implementar Reforma Tributaria. 01 de julio de 2015. https://www.ben.cl/leychile/navegar?i=1079261

Servicio Civil. (2015) Modelo de Liderazgo Institucional. Servicio Civil.

Servicio Civil. (2015). Instructivo Presidencial Buenas Prácticas Laborales en Desarrollo de Personas en el Estado. https://www.serviciocivil.cl/wp-content/uploads/2018/04/2015$\underline{\text { Instructivo-Presidencial-Buenas-Pr\%C3\%A1cticas-Laborales-en-Desarrollo-de-Personas- }}$ en-el-Estado.pdf

Servicio Civil. (2015). Modelo Gestión de Personas. https://www.serviciocivil.cl/wpcontent/uploads/2018/04/Modelo-de-Gestion-de-Personas.pdf

Servicio de Impuestos Internos (2015). Protocolo de acuerdo entre el Gobierno y Asociaciones de Funcionarios del SII. Asociación Nacional de Funcionarios del SII (ANEIICH).

http://www.aneiichdndgc.cl/archivos_2015/FIRMA_PROTOCOLO_PROYECTO_DE_LE Y_FORTALECIMIENTO_DEL_SII_27_ENERO_2015.pdf

Servicio de Impuestos Internos. (2015). Plan Estratégico Institucional 2015-2018. https://www.sii.cl/sobre_el_sii/plan_estrategico_sii.pdf

Servicio de Impuestos Internos. (2016) Protocolo de funcionamiento de mesas de trabajo regionales. Servicio de Impuestos Internos.

Servicio de Impuestos Internos. (2016). Política Institucional de Desarrollo de Personas del Servicio de Impuestos Internos. https://aneiich.cl/wpcontent/uploads/2020/06/Pol\%A1tica-Desarrollo-de-Personas.pdf 